\title{
Analisis Pola Karakteristik Suara pada Kasus Forensik
}

\author{
Dedy Prasetyo ${ }^{1} *$ \\ ${ }^{1}$ Laboratorium Forensik Polri Cabang Surabaya \\ * email : s.d.prasetyo@gmail.com
}

\begin{abstract}
Analysis of voice characteristic pattern has an important role in the forensic science. It can apply to solve criminal cases in order to straighten justice and law in the Criminal Justice System. This study tries to analyze the pattern of voice print by comparing the evidence of recorded sound from the mobile phone with the sound of testee to determine their equality or difference. In answering the problem stated in the research hypothesis, then used comprehensive analysis based on voice acoustical characteristics, $e$. g. : spectrogram analysis, pitch statistical analysis, formant and formant bandwidth statistical analysis. Based on statistical test criteria with level of significance $\alpha=0,05$ reveals that the sound of evidence and the sound of testee are equal. Those sounds come from one person, in such a way that we can determine a suspect.
\end{abstract}

Key words : Voice Analysis, Forensic Science, Criminal Justice System.

\section{PENDAHULUAN}

Analisis pola karakteristik suara merupakan salah satu penerapan Ilmu Fisika pada bidang Forensik yang sangat menarik untuk dibicarakan (Tontarski, 2001). Identifikasi suara secara forensik mulai digunakan sebagai alat bukti di dalam persidangan. Dalam pengungkapan identitas tersebut, sampel suara yang tidak dikenal dibandingkan dengan sampel suara yang telah dikenal (Reynolds, 2002). Sampel suara dapat berasal dari rekaman telepon rumah maupun telepon seluler. Barang bukti rekaman suara ini selanjutnya dianalisis untuk menentukan adanya seorang tersangka (Al-Azhar, 2011).

Beberapa penelitian telah dilakukan sebelumnya, antara lain oleh Silalahi pada 2012. Sebelumnya Francis Nolan, et al. (2006) berusaha menyelidiki tentang dinamisasi pada suara manusia sehingga menghasilkan keragaman bunyi dan bahasa. Penelitian tersebut kemudian dilanjutkan oleh Mireia Farrus dari Department of Signal Theory and Communications Universitat Barcelona pada bulan Juli 2008. Dalam penelitiannya, Farrus menemukan bahwa karakteristik seorang pembicara merupakan gabungan antara informasi prosodik dan akustik dalam menghasilkan bunyi berupa kata atau frase. Selanjutnya telah dilaksanakan pula studi dan pembahasan mengenai perlunya kemampuan yang harus dimiliki oleh seorang investigator atau penyidik dalam menangani kasus-kasus yang berhubungan dengan bidang audio forensik (Koenig, 2011).

Berdasarkan uraian tersebut di atas, maka penelitian mengenai analisis suara demi memecahkan kasus-kasus forensik sangat penting untuk dilakukan mengingat masih terbatasnya data-data dan pembahasan mengenainya. Seiring dengan perkembangan jaman, tingkat kriminalitas juga semakin meningkat. Menurut Abdussalam (2006), penyidik dan pemeriksa forensik dituntut mampu menjawab tantangan ini, untuk membantu penegakan hukum sebagai saksi ahli. Sampel suara pada rekaman barang bukti dapat dikenali secara awam, namun alat bukti tersebut lemah karena masih bersifat subjektif serta dapat disangkal keberadaannya. Selain itu, terkadang didapatkan barang bukti dengan kualitas rekaman suara kurang baik atau tidak begitu jelas, sehingga memerlukan pengolahan dan perlakuan yang lebih spesifik terlebih dahulu sebelum diperiksa. Untuk itu, seorang saksi ahli/pemeriksa forensik dalam menganalisis bukti petunjuk rekaman suara harus sesuai dengan prosedur yang berlaku, objektif, dan berlandaskan pada metode ilmiah (Siegel, 2009). Melalui penelitian ini, diharapkan dapat diketahui penentuan pola karakteristik suara barang bukti (unknown/questioned samples) dengan membandingkannya terhadap suara terperiksa (known samples) secara komprehensif di Laboratorium Forensik Polri. 


\section{METODE PENELITIAN}

Penelitian ini adalah penelitian analitik observasional dengan metode pengumpulan data cross sectional yang dikaji secara kuantitatif. Pengkajian secara kuantitatif dilakukan dengan uji statistik terhadap data yang menjadi subjek penelitian. Dalam hal ini membandingkan rerata karakteristik pitch, formant, dan formant bandwidth dari barang bukti rekaman suara (unknown samples) terhadap suara pembanding (known samples). Hasil analisis terhadap data tersebut dapat menunjukkan bahwa suara yang dipermasalahkan berasal dari individu yang sama atau berbeda.

\section{Sampel Penelitian}

Sampel dalam penelitian ini adalah rekaman suara barang bukti di dalam hand phone yang ditemukan di tempat kejadian perkara dan sampel suara pembanding berupa rekaman suara subjek terperiksa yang direkam di laboratorium. Masing-masing sampel memiliki karakteristik, antara lain : spectrogram, pitch, formant, dan formant bandwidth.

\section{Instrumen Penelitian}

Instrumen penelitian terdiri dari hardware (perangkat keras), berupa : Komputer Analisis Digital Forensik dan software, berupa : Aplikasi Praat 5340, Audacity, Gnumeric 1.10.1620110616, dan SPSS 20.

\section{Analisis Data}

Setelah didapatkan data-data relevan, selanjutnya ditentukan apakah kedua suara tersebut identik atau berbeda. Langkah pertama adalah uji kualitatif dengan analisis spectrogram untuk membandingkan sidik suara barang bukti dengan pembanding. Apabila tidak ada kecocokan antara gambar sidik suara barang bukti dengan pembanding, maka dapat disimpulkan bahwa hasil komparasi kedua suara tersebut adalah tidak identik. Tetapi bila dapat diduga adanya kecocokan antara suara barang bukti dengan suara pembanding, maka perlu diteruskan ke langkah selanjutnya untuk uji kuantitatif terhadap nilai-nilai frekuensi.

\section{Proses Identifikasi Suara}

Proses Identifikasi Suara (Rose, 2002) dilakukan untuk memeriksa kedua rekaman suara barang bukti maupun pembanding. Rekaman suara disimpan dalam bentuk file wav. Selanjutnya, dibuat notasi Pitch, Formant, dan Spectrogram agar dapat langsung dilakukan analisis lebih lanjut. Berikut adalah tampilan Praat Picture yang menunjukkan pola dan karakteristik suara.

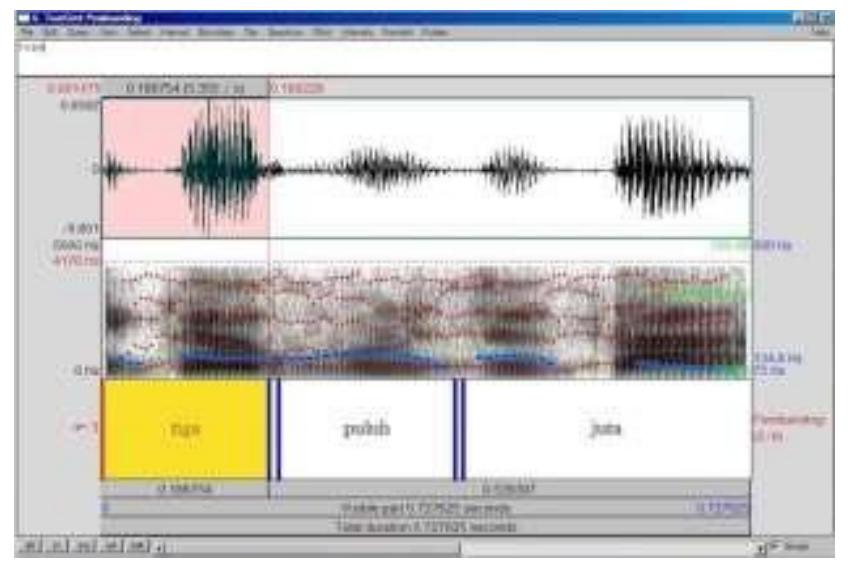

Gambar 1. Tampilan Praat Picture yang menunjukkan pola karakteristik suara.

Terlihat pada gambar bagian atas merupakan bentuk spektrum frekuensi frase "tiga puluh juta" yang diucapkan subjek terperiksa pada proses transkripsi. Pada gambar bagian bawah garis merah adalah formant, biru adalah pitch, kuning adalah intensitas suara, dan pada latar belakangnya nampak pola spectrogram suara subjek terperiksa. 


\section{HASIL DAN PEMBAHASAN}

\section{Analisis Spectrogram}

Analisis spectrogram merupakan tahap awal dalam proses identifikasi suara. Gambar spektrum suara barang bukti yang muncul dibandingkan dengan gambar spektrum suara pembanding untuk tiap-tiap kata atau frase yang diucapkan.

Dari hasil penelitian, gambar spektrum suara barang bukti ketika mengucapkan kata "tiga" disajikan berdampingan dengan gambar spektrum pembanding ketika mengucapkan kata yang sama agar dapat dianalisis. Spectrogram suara tersebut nampak di bawah ini.

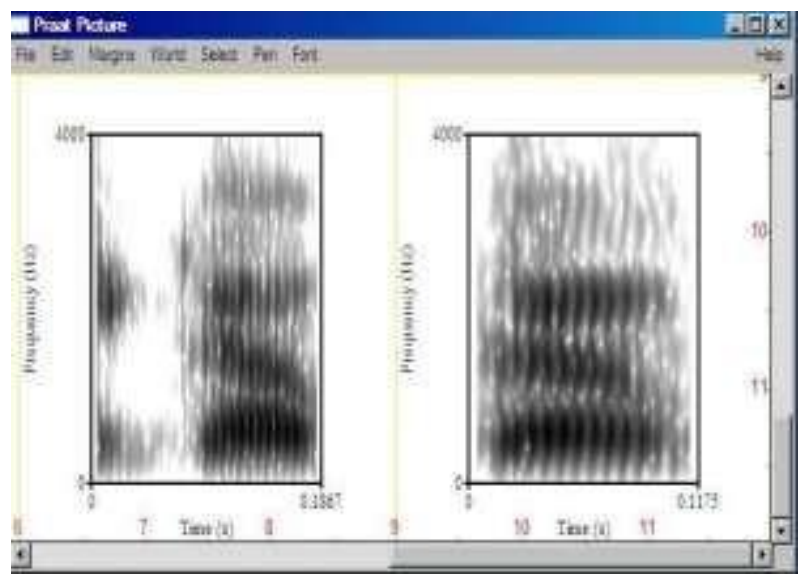

Gambar 2. Spectrogram Pembanding (kiri) dan BarangBukti (kanan) untuk pengucapan kata "tiga"

Terlihat bahwa, gambar spektrum Suara Pembanding untuk pengucapan kata "tiga" memiliki pola yang mirip dengan gambar spektrum Suara BarangBukti untuk pengucapan kata yang sama. Hal ini merupakan indikasi awal bahwa terdapat persamaan antara rekaman suara yang tidak dikenal dengan suara subjek terperiksa.

Selanjutnya adalah proses analisis spectrogram terhadap pengucapan kata "puluh".

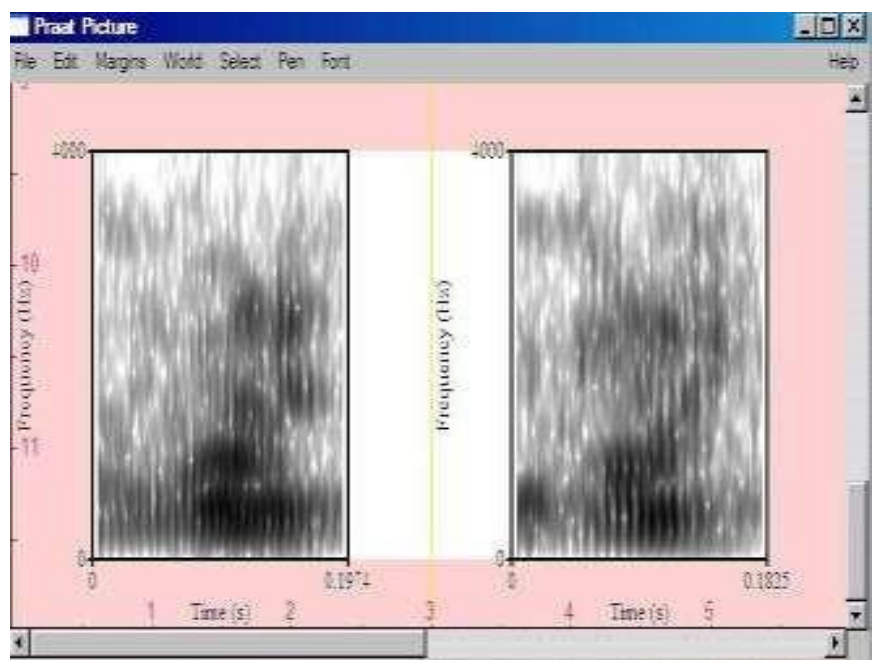

Gambar 3. Spectrogram Pembanding (kiri) dan BarangBukti (kanan) untuk pengucapan kata "puluh".

Tampak jelas bahwa pola spectrogram antara Suara Pembanding dan Suara BarangBukti adalah sama atau identik. Seperti halnya pada proses identifikasi kepolisian dengan metode sidik jari, dimana sidik jari yang ditemukan di tempat kejadian perkara dicocokkan dengan sidik jari seorang tersangka. Bedanya, pencocokan sidik suara tidak hanya secara kualitatif yakni hanya 
membandingkan antara gambar spektrum suara barang bukti dengan gambar spektrum suara tersangka. Lebih jauh lagi, dilakukan uji kuantitatif dengan melakukan analisis statistik terhadap nilai-nilai frekuensi suara yang merupakan karakteristiknya. Hasilnya bersifat akurat dan verifikatif, sehingga dapat menjadi alat bukti yang kuat di dalam persidangan. Tidak lagi subjektif, yakni hanya mengandalkan pada keterangan saksi yang bisa dipengaruhi kondisi tertentu.

Pada langkah selanjutnya, dilakukan pula proses yang sama yakni mencocokkan antara Spectrogram Pembanding dan Spectrogram BarangBukti untuk pengucapan kata “juta”.

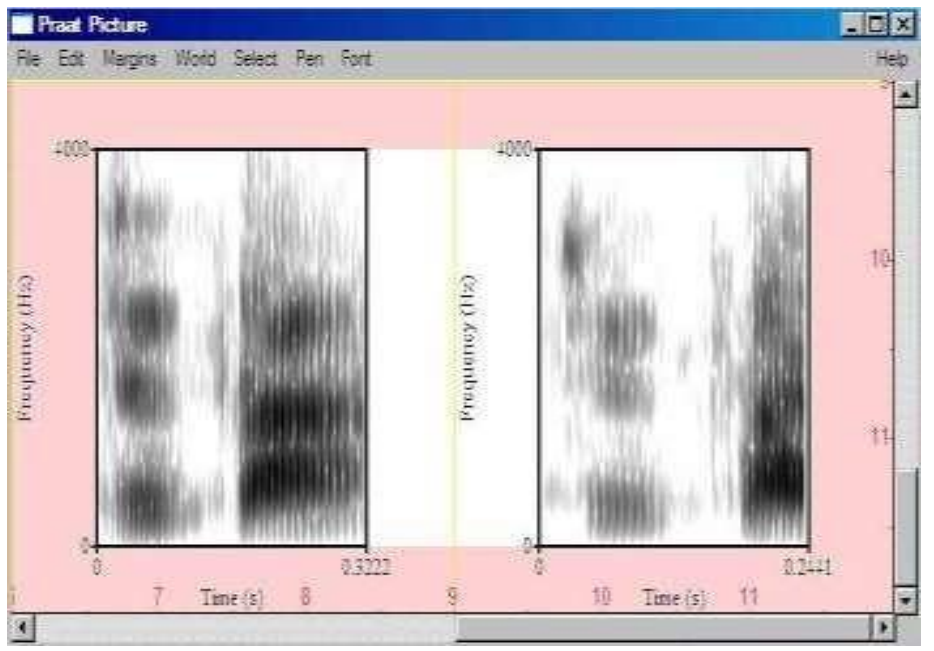

Gambar 4. Spectrogram Pembanding (kiri) dan BarangBukti (kanan) untuk pengucapan kata "juta”.

Terlihat bahwa gambar spektrum Suara BarangBukti di sebelah kanan nampak samar bila dibandingkan dengan gambar spektrum Suara Pembanding yang terletak di sebelah kirinya. Hal ini karena perbedaan lokasi pada saat kata tersebut diucapkan.

Pengucapan Suara BarangBukti pada lokasi saat terjadinya kasus/peristiwa sesungguhnya sehingga banyak terdapat noise, sedangkan pengucapan Suara Pembanding direkam dengan menggunakan alat perekam di ruangan yang kedap suara sehingga berbeda kualitas suaranya.

Namun demikian, perbedaan tersebut tidak akan mempengaruhi pola spectrogram yang muncul. Analog dengan barang bukti sidik jari yang ditemukan di tempat kejadian perkara. Walaupun samar-samar atau kurang jelas, apabila pelaku sebenarnya memang berada di lokasi pada saat terjadinya peristiwa, maka pencocokan antara kedua sidik jari yakni barang bukti dengan tersangka akan memberikan hasil yang identik sehingga tersangka tidak dapat mengelak atas keberadaannya.

Dari analisis spectrogram terhadap Suara BarangBukti dan Suara Pembanding untuk pengucapan kata "tiga", "puluh", dan "juta" menunjukkan hasil yang identik. Jadi terdapat persamaan antara pola spectrogram barang bukti dengan pembanding yang diteliti, atau dengan kata lain suara barang bukti (unknown samples) dan suara pembanding (known samples) berasal dari satu orang yang sama.

\section{Analisis Statistik Pitch}

Analisis Statistik Pitch merupakan langkah kedua dalam proses identifikasi suara. Hal tersebut dilakukan sebagai uji kuantitatif untuk membandingkan nilai-nilai frekuensi pitch antara Suara BarangBukti dengan Suara Pembanding. Pitch adalah karakteristik frekuensi dasar tiap individu dalam satuan hertz. Perbedaan antara pitch dengan formant ialah bahwa pitch tidak dipengaruhi oleh artikulator bunyi.

Hasil perhitungan terhadap nilai frekuensi pitch antara Suara BarangBukti dan Suara Pembanding untuk pengucapan frase "tiga puluh juta" ditunjukkan sebagaimana tabel berikut di bawah. 
Tabel 1. Perhitungan frekuensi Pitch untuk frase "tiga puluh juta".

\begin{tabular}{|l|c|c|}
\hline Perhitungan Pitch & Suara BarangBukti & Suara Pembanding \\
\hline Frekuensi Minimum & $126.861458514296 \mathrm{~Hz}$ & $125.15209024316 \mathrm{~Hz}$ \\
\hline Frekuensi Maksimum & $146.930626476437 \mathrm{~Hz}$ & $151.48416897706 \mathrm{~Hz}$ \\
\hline Frekuensi Median & $130.284941570037 \mathrm{~Hz}$ & $134.60131115003 \mathrm{~Hz}$ \\
\hline Frekuensi Rerata & $134.465390317712 \mathrm{~Hz}$ & $132.00181273294 \mathrm{~Hz}$ \\
\hline Simpangan Baku & $5.446268642527 \mathrm{~Hz}$ & $8.27042119419 \mathrm{~Hz}$ \\
\hline Jumlah n & 26 & 25 \\
\hline
\end{tabular}

Dari data terlihat rerata frekuensi Pitch Suara BarangBukti untuk pengucapan frase "tiga puluh juta" sebesar 134,46 \pm 5,45 Hz. Sedangkan Suara Pembanding sebesar 132,00 \pm 8,27 Hz. Varians gabungan/pooled variance dari hasil perhitungan sebesar 6,98. Derajat kebebasan df $=49$.

Dari hasil perhitungan didapatkan bahwa t hitung $=1,26$, sedangkan dari tabel didapatkan $\mathrm{t}$ tabel $=2,01$ pada taraf signifikan $\alpha=0,05$. Hasil uji statistik menunjukkan bahwa rerata frekuensi Pitch Suara BarangBukti dengan Suara Pembanding untuk pengucapan frase "tiga puluh juta" berada pada daerah penerimaan Ho atau tidak menunjukkan adanya perbedaan. Jadi suara tersebut berasal dari orang yang sama.

Untuk lebih mempertajam kesimpulan dari Analisis Pitch tersebut di atas, selanjutnya akan dilakukan fragmentasi kata demi kata yang masing-masing frekuensinya juga akan dianalisis statistik pitch. Berikut ini adalah tabel hasil pengamatan frekuensi pitch antara Suara BarangBukti dan Suara Pembanding untuk pengucapan kata "tiga".

Tabel 2. Hasil perhitungan frekuensi Pitch untuk kata "tiga"

\begin{tabular}{|l|c|c|}
\hline Perhitungan Pitch & Suara BarangBukti & Suara Pembanding \\
\hline Frekuensi Minimum & $117.94212509097 \mathrm{~Hz}$ & $119.95306667263 \mathrm{~Hz}$ \\
\hline Frekuensi Maksimum & $141.39148360356 \mathrm{~Hz}$ & $146.30668321162 \mathrm{~Hz}$ \\
\hline Frekuensi Median & $125.00821325819 \mathrm{~Hz}$ & $136.70889252112 \mathrm{~Hz}$ \\
\hline Frekuensi Rerata & $130.02836351676 \mathrm{~Hz}$ & $132.01291941980 \mathrm{~Hz}$ \\
\hline Simpangan Baku & $4.41932787200 \mathrm{~Hz}$ & $8.01393493634 \mathrm{~Hz}$ \\
\hline Jumlah n & 26 & 25 \\
\hline
\end{tabular}

Dari tabel, rerata frekuensi Pitch Suara BarangBukti untuk pengucapan kata "tiga" sebesar $130,03 \pm 4,42 \mathrm{~Hz}$. Sedangkan Suara Pembanding sebesar 132,01 \pm 8,01 Hz. Varians gabungan/pooled variance dari hasil perhitungan sebesar 6,43. Derajat kebebasan df $=49$.

Dari hasil perhitungan didapatkan bahwa t hitung $=-1,10$, sedangkan dari tabel didapatkan $\mathrm{t}$ tabel $=2,01$ pada taraf signifikan $\alpha=0,05$. Hasil uji statistik menunjukkan bahwa rerata frekuensi Pitch Suara BarangBukti dengan Suara Pembanding untuk pengucapan kata "tiga" tidak menunjukkan adanya perbedaan, dengan kata lain suara tersebut identik atau berasal dari orang yang sama.

Langkah yang sama dilakukan untuk fragmentasi kata "puluh", menunjukkan hasil perhitungan sebagaimana berikut ini.

Tabel 3. Hasil perhitungan frekuensi Pitch untuk kata "puluh".

\begin{tabular}{|l|l|l|}
\hline Perhitungan Pitch & Suara BarangBukti & Suara Pembanding \\
\hline Frekuensi Minimum & $114.91519469852 \mathrm{~Hz}$ & $117.17971510965 \mathrm{~Hz}$ \\
\hline Frekuensi Maksimum & $131.48495737980 \mathrm{~Hz}$ & $133.46203678817 \mathrm{~Hz}$ \\
\hline
\end{tabular}




\begin{tabular}{|l|c|r|}
\hline Frekuensi Median & $130.36677921516 \mathrm{~Hz}$ & $125.60349474352 \mathrm{~Hz}$ \\
\hline Frekuensi Rerata & $123.26274138794 \mathrm{~Hz}$ & $125.21471658637 \mathrm{~Hz}$ \\
\hline Simpangan Baku & $7.65327153910 \mathrm{~Hz}$ & $9.69940075481 \mathrm{~Hz}$ \\
\hline Jumlah n & 26 & 25 \\
\hline
\end{tabular}

Dari data menunjukkan rerata frekuensi Pitch Suara BarangBukti untuk pengucapan kata "puluh" sebesar 123,26 \pm 7,65 Hz. Sedangkan Suara Pembanding sebesar 125,22 \pm 9,70 Hz. Varians gabungan/pooled variance dari hasil perhitungan sebesar 8,71. Derajat kebebasan df $=49$.

Dari hasil perhitungan didapatkan bahwa t hitung $=-0,80$, sedangkan dari tabel didapatkan $\mathrm{t}$ tabel $=2,01$ pada taraf signifikan $\alpha=0,05$. Hasil uji statistik tersebut menunjukkan bahwa rerata frekuensi Pitch Suara BarangBukti dengan Suara Pembanding untuk pengucapan kata "puluh" menunjukkan adanya kesamaan. Jadi suara tersebut adalah identik.

Sedangkan fragmentasi kata "juta" menunjukkan hasil perhitungan frekuensi pitch sebagaimana disajikan pada tabel berikut di bawah ini.

Tabel 4. Hasil perhitungan frekuensi Pitch untuk kata "juta”.

\begin{tabular}{|l|c|c|}
\hline Perhitungan Pitch & Suara BarangBukti & Suara Pembanding \\
\hline Frekuensi Minimum & $117.29666362236 \mathrm{~Hz}$ & $115.33626942134 \mathrm{~Hz}$ \\
\hline Frekuensi Maksimum & $137.23088971719 \mathrm{~Hz}$ & $135.00923202064 \mathrm{~Hz}$ \\
\hline Frekuensi Median & $128.50088000552 \mathrm{~Hz}$ & $129.66598253791 \mathrm{~Hz}$ \\
\hline Frekuensi Rerata & $131.80668104068 \mathrm{~Hz}$ & $132.85053019632 \mathrm{~Hz}$ \\
\hline Simpangan Baku & $5.48310762813 \mathrm{~Hz}$ & $8.31973681098 \mathrm{~Hz}$ \\
\hline Jumlah n & 26 & 25 \\
\hline
\end{tabular}

Berdasarkan data, terlihat bahwa rerata frekuensi Pitch Suara BarangBukti untuk pengucapan kata "juta" sebesar 131,81 \pm 5,48 Hz. Sedangkan Suara Pembanding sebesar 132,85 \pm 8,32 Hz. Varians gabungan/pooled variance dari hasil perhitungan sebesar 7,02. Derajat kebebasan df $=49$.

Dari hasil perhitungan didapatkan bahwa t hitung $=-0,53$, sedangkan dari tabel didapatkan $\mathrm{t}$ tabel $=2,01$ pada taraf signifikan $\alpha=0,05$. Hasil uji statistik tersebut menunjukkan bahwa rerata frekuensi Pitch Suara BarangBukti dengan Suara Pembanding untuk pengucapan kata "juta" tidak menunjukkan adanya perbedaan. Jadi suara tersebut adalah berasal dari subjek yang sama.

Dari Analisis Statistik Pitch yang telah dilakukan di atas, dapat ditarik kesimpulan bahwa nilai frekuensi pitch Suara BarangBukti identik dengan frekuensi pitch Suara Pembanding dalam interval konfidensi $95 \%$.

\section{Analisis Statistik Formant dan Formant Bandwidth}

Sebagaimana halnya analisis statistik terhadap frekuensi pitch, dilakukan pula analisis statistik terhadap tiap-tiap frekuensi formant maupun bandwidthnya. Hal ini berguna apabila subjek terperiksa berusaha melakukan counter measure pada saat dilakukan proses transkripsi dalam pemeriksaan.

Karakteristik suara berupa formant bandwidth merupakan lebar rentang frekuensi formant itu sendiri, sehingga formant bandwidth memiliki kekhasan dan memerlukan analisis statistik tersendiri pula.

Berikut di bawah ini adalah hasil pengamatan terhadap nilai-nilai frekuensi formant dan formant bandwidth yang dihasilkan oleh Suara BarangBukti dan Suara Pembanding pada sampel pengucapan frase yang telah ditentukan sebelumnya. 


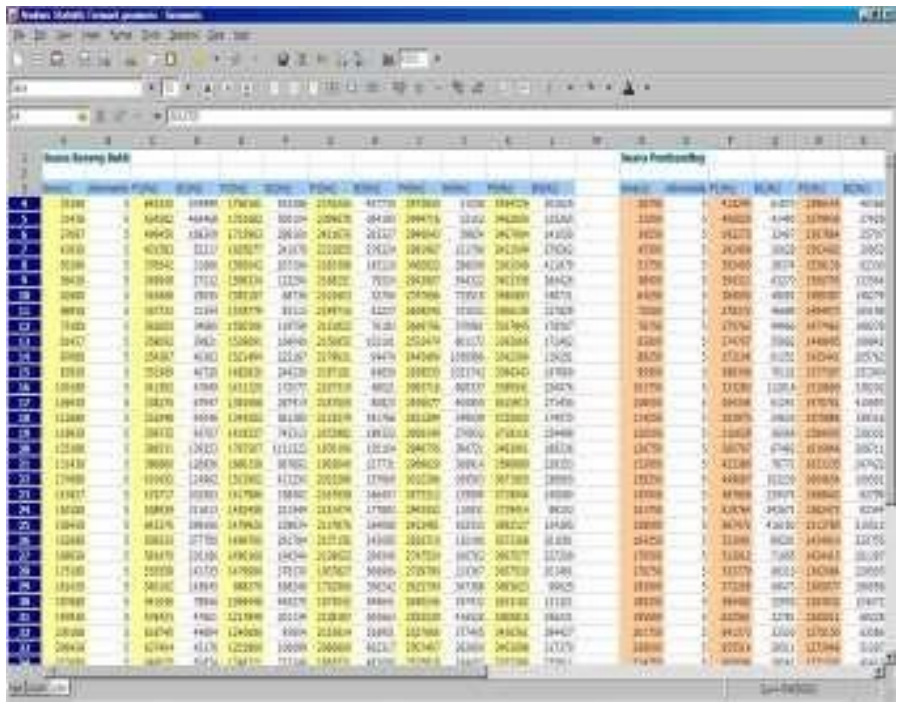

Gambar 5. Tampilan Frekuensi Formant dan Formant Bandwidth.

Dari hasil pengamatan nilai-nilai frekuensi formant dan formant bandwidth yang telah didapatkan tersebut, selanjutnya akan dilakukan analisis secara statistik untuk menentukan adanya persamaan atau perbedaan antara Suara BarangBukti dan Suara Pembanding ditinjau dari karakteristik suara Formant dan Formant Bandwidth.

Menurut Arief Wibowo, dkk (2007), apabila terdapat dua sampel berbeda dan tidak berkaitan yang masing-masing diamati sekali maka dapat digunakan uji t dua sampel bebas untuk melihat ada tidaknya perbedaan.

Berlakunya uji tersebut karena memenuhi beberapa kriteria berikut :

a. Skala pengukuran data : interval dan rasio (kuantitatif).

b. Sampel berasal dari populasi berdistribusi normal atau kurva normal.

c. Digunakan untuk dua sampel yang independen.

d. Bertujuan membandingkan (uji komparasi) rata-rata kelompok data I dan II.

Sebelum dilakukan uji t, dipastikan dengan uji $\mathrm{F}$ terlebih dahulu untuk menentukan homogenitas varians. Hipotesis yang diajukan (Boediono, 2002) adalah terdapat kesamaan variansi nilai frekuensi Formant antara Suara BarangBukti dan Suara Pembanding. Setelah dilakukan uji F untuk menentukan kelompok data bersifat homogen atau heterogen, selanjutnya diselesaikan dengan uji $\mathrm{t}$ untuk menguji hipotesis tentang kesamaan nilai frekuensi formant dan formant bandwidth antara Suara BarangBukti dan Suara Pembanding.

Hasil pengujian Analisis Statistik Formant dan Formant Bandwidth antara Suara BarangBukti dan Suara Pembanding pada pengucapan kata "tiga" dirangkum dalam tabel berikut ini.

Tabel 5. Analisis Statistik Formant dan Formant Bandwidth untuk pengucapan kata "tiga".

\begin{tabular}{|l|c|c|c|c|c|}
\hline $\begin{array}{l}\text { Frekuensi } \\
\text { Karakteristik }\end{array}$ & Fitung & F & tritung $^{\text {tabel }}$ & t $^{\text {tabel }}$ & Kesimpulan \\
\hline Formant 1 & 22,114625 & 2,763602 & 1,149122 & 2,061461 & Terima Ho \\
\hline Formant 2 & 2,2465113 & 2,763602 & 0,812748 & 2,039513 & Terima Ho \\
\hline Formant 3 & 13,718298 & 2,763602 & 4,095988 & 2,054046 & Tolak Ho \\
\hline Formant 4 & 0,596338 & 2,763602 & 0,395857 & 2,039513 & Terima Ho \\
\hline Formant 5 & 0,684921 & 2,763602 & 0,767964 & 2,039513 & Terima Ho \\
\hline F. Bandwidth 1 & 124,97019 & 2,763602 & 2,202918 & 2,075729 & Tolak Ho \\
\hline F. Bandwidth 2 & 537,88291 & 2,763602 & 2,786721 & 2,078681 & Tolak Ho \\
\hline F. Bandwidth 3 & 0,397572 & 2,763602 & 0,505578 & 2,039513 & Terima Ho \\
\hline
\end{tabular}




\begin{tabular}{|c|c|c|c|c|c|}
\hline F. Bandwidth 4 & 6,772166 & 2,763602 & 0,243197 & 2,042903 & Terima Но \\
\hline F. Bandwidth 5 & 1,559679 & 2,763602 & 1,496831 & 2,039513 & Terima Но \\
\hline
\end{tabular}

Dari data-data yang terlihat pada tabel di atas, secara umum menunjukkan adanya kesamaan antara frekuensi Formant dan Formant Bandwidth Suara BarangBukti dan Suara Pembanding untuk pengucapan kata "tiga".

Ho diterima, berarti pada taraf signifikan $\alpha=0,05$, tidak ada perbedaan rerata frekuensi karakteristik dari Suara BarangBukti dengan rerata frekuensi karakteristik dari Suara Pembanding untuk pengucapan kata "tiga".

Namun pada beberapa nilai frekuensi karakteristik sebagaimana tercantum di atas terdapat pula kesimpulan Ho ditolak, yakni pada Formant 3, Formant Bandwith 1, dan Formant Bandwidth 2. Hal ini dapat disebabkan oleh beberapa faktor, misalnya subjek terperiksa berupaya melakukan counter measure, yakni dengan mengubah intensitas suara. Akan tetapi ia tidak akan mampu sepenuhnya mengontrol semua formant maupun formant bandwidth agar berbeda dengan suara aslinya.

Hasil pengujian Analisis Statistik Formant dan Formant Bandwidth antara Suara BarangBukti dan Suara Pembanding pada pengucapan kata "puluh" disajikan pada tabel di bawah ini.

Tabel 6. Analisis Statistik Formant dan Formant Bandwidth untuk pengucapan kata "puluh".

\begin{tabular}{|l|c|c|c|c|c|}
\hline $\begin{array}{l}\text { Frekuensi } \\
\text { Karakteristik }\end{array}$ & $\mathbf{F}_{\text {hitung }}$ & $\mathbf{F}_{\text {tabel }}$ & $\mathbf{t}_{\text {hitung }}$ & $\mathbf{t}_{\text {tabel }}$ & Kesimpulan \\
\hline Formant 1 & 0,608432 & 2,063280 & 0,004457 & 2,015368 & Terima Ho \\
\hline Formant 2 & 0,924873 & 2,063280 & 1,057619 & 2,015368 & Terima Ho \\
\hline Formant 3 & 1,263301 & 2,063280 & 0,621757 & 2,015368 & Terima Ho \\
\hline Formant 4 & 0,527217 & 2,063280 & 2,053420 & 2,015368 & Tolak Ho \\
\hline Formant 5 & 0,616143 & 2,063280 & 0,817904 & 2,015368 & Terima Ho \\
\hline F. Bandwidth 1 & 1,228200 & 2,063280 & 2,633504 & 2,015368 & Tolak Ho \\
\hline F. Bandwidth 2 & 1,567490 & 2,063280 & 0,185230 & 2,015368 & Terima Ho \\
\hline F. Bandwidth 3 & 1,677112 & 2,063280 & 4,173152 & 2,015368 & Tolak Ho \\
\hline F. Bandwidth 4 & 1,781525 & 2,063280 & 0,243386 & 2,015368 & Terima Ho \\
\hline F. Bandwidth 5 & 1,718496 & 2,063280 & 0,817345 & 2,015368 & Terima Ho \\
\hline
\end{tabular}

Berdasarkan data-data dari tabel di atas, menunjukkan adanya kecocokan antara Suara BarangBukti dan Suara Pembanding untuk pengucapan kata "puluh" ditinjau dari frekuensi Formant dan Formant Bandwidth. Sebagian besar kesimpulan menunjukkan bahwa Ho diterima. Hal tersebut menunjukkan fakta bahwa pada interval konfidensi 95\%, rerata frekuensi karakteristik dari Suara BarangBukti dan rerata frekuensi karakteristik dari Suara Pembanding untuk pengucapan kata "puluh" memiliki kesamaan.

Ada beberapa nilai frekuensi karakteristik yang menghasilkan kesimpulan tolak Ho sehingga terima Ha (Supranto, 2009), yakni pada Formant 4, Formant Bandwith 1, dan Formant Bandwidth 3. Hal ini disebabkan masih terdapatnya upaya tersangka untuk melakukan counter measure agar keidentikan suaranya tidak terdeteksi oleh instrumen. Namun sebagian besar kesimpulan tetap menunjukkan hasil terima Ho, sehingga Analisis Statistik Formant dan Formant Bandwidth terhadap Suara BarangBukti dan Suara Pembanding untuk pengucapan kata "puluh" adalah identik.

Berikut di bawah ini terdapat tabel yang menuangkan hasil pengujian Analisis Statistik Formant dan Formant Bandwidth antara Suara BarangBukti dan Suara Pembanding pada pengucapan kata "juta". 
Tabel 7. Analisis Statistik Formant dan Formant Bandwidth untuk pengucapan kata "juta".

\begin{tabular}{|l|c|c|c|c|c|}
\hline $\begin{array}{l}\text { Frekuensi } \\
\text { Karakteristik }\end{array}$ & F & F $^{\text {tabel }}$ & $\mathbf{t}^{\text {hitung }}$ & t $^{\text {tabel }}$ & Kesimpulan \\
\hline Formant 1 & 1,260787 & 1,768243 & 1,447362 & 1,992544 & Terima Ho \\
\hline Formant 2 & 0,459050 & 1,768243 & 1,555695 & 1,992544 & Terima Ho \\
\hline Formant 3 & 0,843110 & 1,768243 & 0,335351 & 1,992544 & Terima Ho \\
\hline Formant 4 & 3,265009 & 1,768243 & 1,978463 & 1,994589 & Terima Ho \\
\hline Formant 5 & 0,735005 & 1,768243 & 0,445054 & 1,992544 & Terima Ho \\
\hline F. Bandwidth 1 & 0,337025 & 1,768243 & 2,564045 & 1,992544 & Tolak Ho \\
\hline F. Bandwidth 2 & 0,150219 & 1,768243 & 5,161287 & 1,992544 & Tolak Ho \\
\hline F. Bandwidth 3 & 2,588540 & 1,768243 & 1,983975 & 1,993249 & Terima Ho \\
\hline F. Bandwidth 4 & 3,096530 & 1,768243 & 1,402201 & 1,994233 & Terima Ho \\
\hline F. Bandwidth 5 & 0,791586 & 1,768243 & 0,403084 & 1,992544 & Terima Ho \\
\hline
\end{tabular}

Dari data-data yang terlihat pada tabel di atas, secara umum menunjukkan adanya kesamaan antara frekuensi Formant dan Formant Bandwidth Suara BarangBukti dan Suara Pembanding untuk pengucapan kata "juta".

Ho diterima, berarti $95 \%$ dapat dipercaya bahwa tidak terdapat perbedaan rerata frekuensi karakteristik dari Suara BarangBukti dengan rerata frekuensi karakteristik dari Suara Pembanding untuk pengucapan kata "juta" (atau dengan kata lain : suara tersebut berasal dari orang yang sama).

\section{KESIMPULAN}

1. Analisis pola spectrogram suara barang bukti dengan pembanding yang diteliti, menunjukkan bahwa secara kualitatif terdapat persamaan atau dengan kata lain suara barang bukti (unknown samples) dan suara pembanding (known samples) berasal dari satu orang yang sama.

2. Analisis secara kuantitatif terhadap karakteristik suara barang bukti dengan suara pembanding, meliputi :

a. Analisis statistik pitch, menunjukkan bahwa pada taraf signifikan $\alpha=0,05$, tidak terdapat perbedaan rerata frekuensi pitch antara suara barang bukti dan suara pembanding.

b. Analisis statistik formant 1, 2, 3, 4, dan 5 terhadap suara barang bukti dan suara pembanding, secara umum menunjukkan bahwa suara barang bukti identik dengan suara pembanding pada interval konfidensi $95 \%$.

c. Analisis statistik formant bandwidth 1, 2, 3, 4, dan 5 terhadap suara barang bukti dan suara pembanding, secara umum menunjukkan bahwa suara barang bukti identik dengan suara pembanding pada interval konfidensi $95 \%$.

\section{DAFTAR PUSTAKA}

Abdussalam, H. R., 2006, Forensik, Penerbit Restu Agung, Jakarta, 1-11.

Al-Azhar, M. N., 2011, Audio Forensik : Teori dan Analisis, Pelatihan Peningkatan Kemampuan Operasional Fungsi Audio Forensik, 21 Juni, Puslabfor, Jakarta, 1-30.

Boediono dan W. Koster. 2002, Teori dan Aplikasi Statistika dan Probabilitas, P. T. Remaja Rosdakarya Offset, Bandung, 433-434.

Farrus, M., 2008, Fusing Prosodic and Acoustic Information for Speaker Recognition, PhD Dissertation, TALP Research Center, Department of Signal Theory and Communications Universitat Politecnica Catalunya, Barcelona.

Nolan, F., et al., 2006, A Forensic Phonetic: Study of Dynamic Source of Variability in Speech: The DyVis Project, Journal Australian Speech Science \& Technology, 11 : 13-18.

Reynolds, D. A., 2002, An Overview of Automatic Speaker Recognition Technology, Journal ICASSP MIT, $10: 4072-4075$.

Siegel, Jay A., 2009, Forensic Science : The Basics, Taylor and Francis Group, New York, 5-25. 
Jurnal Biosains Pascasarjana Vol. 20 (2018) pp

(C) (2018) Sekolah Pascasarjana Universitas Airlangga, Indonesia

Silalahi, R. M. P., 2012, The Role of Tone Frequency Characters for Identifying Recognition, Journal of English Language and Culture, Vol. 1 (No. 1), 61-66.

Supranto, J., 2009, Statistik: Teori dan Aplikasi, Penerbit Erlangga, Jakarta, 124-170.

Tontarski, R. E., 2001, Forensic Speech and Audio Analysis Forensic Linguistic, Proceedings of The 13th International Forensic Science Symposium, 16-19 October, ICITAP, Florida, D2: 55-56.

Wibowo, A., dkk, 2007, Modul SPSS, Bagian Biostatistika dan Kependudukan, Universitas Airlangga, Surabaya, 33-38. 